\title{
Long-term safety and efficacy of natalizumab in relapsing-remitting multiple sclerosis: impact on quality of life
}

This article was published in the following Dove Press journal:

Patient Related Outcome Measures

4 April 2014

Number of times this article has been viewed

\author{
Raquel Planas \\ Roland Martin \\ Mireia Sospedra \\ Neuroimmunology and MS \\ Research, Department of \\ Neurology, University of Zurich, \\ Zurich, Switzerland
}

Correspondence: Mireia Sospedra Neuroimmunology and MS Research, Department of Neurology, University of Zurich, Frauenklinikstrasse 26,

809। Zurich, Switzerland

Tel +4l 442553905

Fax +4l 442558864

Email mireia.sospedraramos@usz.ch

\begin{abstract}
Natalizumab was the first monoclonal antibody to be approved for the treatment of relapsing-remitting multiple sclerosis (RRMS) based on its short-term efficacy and overall tolerability. However, the incidence of treatment-associated progressive multifocal leukoencephalopathy (PML), an infection of the brain caused by the John Cunningham virus, jeopardized this efficacious treatment from the beginning. Eight years after licensing of natalizumab, longterm studies confirm the considerable and sustained efficacy of natalizumab, although the PML complication still threatens one of the most successful treatments available for RRMS. During these years, considerable progress has been made in identification of risk factors that allow more effective management of PML risk. In addition, long-term studies to define better when to start or stop treatment and to optimize treatment strategies after cessation of natalizumab are ongoing, and hopefully will improve management and will allow natalizumab to remain as a valuable therapeutic option for patients with highly active RRMS.
\end{abstract}

Keywords: therapy, progressive multifocal leukoencephalopathy, multiple sclerosis

\section{Introduction}

Multiple sclerosis (MS) is a chronic inflammatory, demyelinating, and neurodegenerative disease that affects the central nervous system (CNS). ${ }^{1}$ Affecting over 2 million people worldwide, MS usually starts at 20-40 years of age and is the most common cause of neurological disability in young adults. Although not all genetic and environmental risk factors are known, the etiology of MS involves both complex genetic trait and environmental factors. ${ }^{1}$ There are two major forms of MS. Relapsing-remitting (RR) MS is the most frequent form (85\%-90\%) and affects women about twice as often as men. The majority of patients with RRMS later develop secondary progressive disease. ${ }^{2}$ About $10 \%-15 \%$ of patients present with insidious disease onset and steady progression, termed primary progressive MS. Although the factors responsible for the different disease courses are not completely understood, the relapsing forms of MS seem to be driven mainly by acute inflammation that is initiated by adaptive immune cells, while neurodegeneration and chronic microglia-sustained inflammation seems to play a more important role in the progressive forms of the disease. ${ }^{3}$

Treatment options for RRMS have broadened remarkably in recent years. Glatiramer acetate, interferon (IFN)- $\beta$ preparations, mitoxantrone, natalizumab, fingolimod, alemtuzumab, dimethyl fumarate, and teriflunomide are drugs approved to treat RRMS in several countries and have different efficacy and safety profiles. While glatiramer acetate and IFN- $\beta$ preparations have been used 
to treat MS for more than 20 years and have overall good safety profiles, the more recently approved treatments are more effective but also come with more safety complications.

Natalizumab, a monoclonal antibody against the $\alpha 4$ subunit (CD49d) of $\alpha 4$ integrins ( $\alpha 4 \beta 1$ and $\alpha 4 \beta 7$ ), is one of these new treatments, and is very effective but has a complicated safety profile. $\alpha 4 \beta 1$ integrin is expressed by all leukocytes except neutrophils and serves as an adhesion molecule mediating attachment to endothelial cells. Natalizumab prevents transmigration of leukocytes across the blood-brain barrier and the vascular endothelium of the gut by blocking $\alpha 4 \beta 1$ integrin/vascular cell adhesion molecule-1 and mucosal vascular addressin cell adhesion molecule-1 interaction..$^{48}$

Natalizumab was approved by the US Food and Drug Administration (FDA) in 2004 for RRMS based on its high efficacy and good safety profile even before completion of two placebo-controlled, multicenter Phase III clinical trials, ie, AFFIRM (Natalizumab Safety and Efficacy in RRMS) and SENTINEL (Safety and Efficacy of Natalizumab in Combination with Interferon Beta-1a in Patients with RRMS). ${ }^{9,10}$ Only a few months after approval, a completely unexpected severe complication of natalizumab, ie, three cases of progressive multifocal leukoencephalopathy (PML), were identified in patients with MS and Crohn's disease. ${ }^{11-13}$ The manufacturers voluntarily suspended natalizumab in 2005 pending a safety review. After the review, it was considered that the estimated risk of PML was acceptable given the outstanding demonstrable therapeutic benefits of natalizumab, and the drug was reintroduced in the market in 2006 and approved by the FDA and European Medicines Agency for highly active RRMS, although with a pharmacovigilance plan to minimize the risk of PML. This plan involved a prescribing program developed by the FDA known as TOUCH ${ }^{\circledR}$ (Tysabri Outreach Unified Commitment to Health), which aimed to ensure that only prescribers and patients enrolled in TOUCH could prescribe or receive Tysabri. Eight years after licensing of natalizumab, considerable progress has been made in identification of risk factors for PML and approaches to risk minimization, and long-term studies to define better when to start or stop treatment and to optimize treatment strategies after cessation of natalizumab are ongoing. However, the PML complication still jeopardizes one of the most valuable treatments available for MS. Here we review the long-term efficacy and safety of natalizumab in RRMS and the impact on quality of life.

\section{Efficacy of natalizumab and impact on quality of life Clinical trials}

AFFIRM $^{9}$ and SENTINEL ${ }^{10}$ are two large, randomized, double-blind, placebo-controlled, multicenter Phase III clinical trials that provided the initial data regarding the short-term efficacy and safety of natalizumab in patients with RRMS. AFFIRM compared the efficacy of natalizumab monotherapy (300 mg intravenously every 4 weeks) with placebo, while SENTINEL compared the efficacy of natalizumab when added to IFN- $\beta 1$ a with that of IFN- $\beta 1$ a monotherapy. GLANCE (Glatiramer Acetate and Natalizumab Combination Evaluation) is also a published randomized, 24-week, double-blind, placebo-controlled Phase II clinical trial that evaluated the efficacy, safety, and tolerability of natalizumab when added to glatiramer acetate in patients with RRMS. ${ }^{14}$ The short-term efficacy and impact on quality of life of natalizumab in these clinical trials have been extensively reviewed previously, ${ }^{15,16}$ so are not covered in this review.

\section{Clinical practice and real-life settings}

The efficacy of natalizumab and its impact on quality of life have also been studied in different clinical practice and real-life settings. Natalizumab was approved as a secondline treatment for patients in whom first-line treatments have failed and for patients with rapidly evolving MS. Consequently, patients treated with natalizumab in clinical practice had in general more severe disease than patients in clinical trials, and the majority had received diseasemodifying treatments. For this reason, it was assumed that the efficacy of natalizumab in clinical trials might differ from the experience in clinical practice. Several studies have examined the clinical efficacy of natalizumab in open-label cohorts and shown that these patient populations also benefit from treatment with natalizumab. ${ }^{17-21}$ The effect of natalizumab on Expanded Disability Status Scale (EDSS) scores was evaluated in a retrospective study of patients treated for 44 weeks. In this study, treatment with natalizumab improved EDSS scores mainly in patients who had relapse-mediated worsening of EDSS.2. In addition, other studies also demonstrated an effect of treatment, with natalizumab improving visual acuity ${ }^{23}$ visual evoked potential sum scores,${ }^{24}$ and cognitive performance. ${ }^{25-27}$ In a small, prospective, magnetic resonance imaging (MRI) study, ${ }^{28}$ it was found that treatment with natalizumab over 2 years reduced cortical lesions and cortical atrophy when compared with untreated patients and patients treated with first-line therapies. This observation suggests 
that natalizumab might, by reducing inflammation, generate a more favorable environment for remyelination. Supporting a role for natalizumab in reducing axonal damage, it was observed in a longitudinal cerebrospinal fluid study of 92 MS patients treated with natalizumab that neurofilament light chain, a marker of neurodegeneration, decreased to the levels found in normal donors. ${ }^{29}$

The first evaluation of the early effects of natalizumab on Patient-Reported Outcomes in a clinical setting was performed in MS patients $(n=451)$ enrolled in the TOUCH prescribing program and who received their third natalizumab infusion. This study demonstrated that natalizumab significantly improved overall quality of life from baseline to 3 months of follow-up in $46 \%$ of patients and maintained quality of life in $51 \% .{ }^{30}$ Despite the short treatment duration, there was a significant improvement in disease level and functional status scores. Thirty percent of patients reported an improved functional status and 67\% reported a stable functional status. Eighty percent of patients also reported an improvement in one or more physical items of the 29-item Multiple Sclerosis Impact Scale, in which the ability to perform physically demanding tasks was the item for which the highest improvement was reported. In addition, $75 \%$ of patients reported improvement in one or more psychological items, particularly for feeling well. ${ }^{30}$ In 2012 , the first large, real-life, 12-month longitudinal study assessing the impact of natalizumab on Patient-Reported Outcomes was reported in 333 MS patients. ${ }^{31}$ After 12 months of treatment with natalizumab, $69 \%-88 \%$ of patients reported a positive outcome, either improvement or no decline, in all Patient-Reported Outcomes measures assessed. The improvements were observed as early as after 3 months of treatment and were sustained over a 12-month period. The improvements were observed with physical and psychological measures, and significantly reduced the impact of MS on cognitive functioning and fatigue. ${ }^{31}$

A Swedish survey of natalizumab-treated patients that investigated the monetary value of treatment with natalizumab in terms of the ability to work showed that, after 50 weeks of treatment with natalizumab, MS patients increased their productivity by 3.3 hours per week on average $(P<0.01) .{ }^{32}$ Overall, $22 \%$ of patients increased their work capacity, $6 \%$ decreased their work capacity, and $72 \%$ were unchanged. A shorter duration of disease, younger age at the start of treatment, and being employed rather than self-employed were significantly associated with a greater productivity gain. ${ }^{32}$

The TYNERGY (Effects of Tysabri over 12 months on MS related fatigue in patients with RRMS) study that aimed to further evaluate the effects of treatment with natalizumab on MS-related fatigue has recently been reported..$^{33}$ In this one-armed clinical trial, $195 \mathrm{MS}$ patients were treated with natalizumab in a real-life setting for 12 months, and the effect of treatment on fatigue was evaluated using a validated questionnaire, ie, The Fatigue Scale for Motor and Cognitive Functions. All measured variables, ie, fatigue score, quality of life, sleepiness, depression, cognition, and disability progression, were improved from baseline to 12 months, as well as walking speed measured by the 6 -minute walk test. ${ }^{33}$

\section{Long-term follow-up}

There are two large, ongoing observational studies of note for which some results are partially available. These studies are STRATA (Safety of Tysabri Re-dosing and Treatment) and TOP (Tysabri Observational Program).

STRATA is a long-term (up to 10 years), open-label, multinational, follow-up study of natalizumab monotherapy (300 mg intravenously every 4 weeks) in patients with RRMS who completed the AFFIRM, SENTINEL, and GLANCE trials and their open-label extensions, and is evaluating the long-term safety and efficacy of natalizumab. In March 2013, after 4,135 patient-years of natalizumab exposure in STRATA (median of 64 natalizumab infusions), the annualized relapse rate remained low at 0.15 relapses per patient per year. Mean EDSS scores increased in the time between completing the feeder studies and enrollment in STRATA. Mean EDSS scores for patients who originally received natalizumab or placebo, respectively, were 2.9 and 3.1 at STRATA baseline, 2.7 and 3.1 at week 48, 2.7 and 3.2 at week 96, 2.8 and 3.2 at week 144, 2.9 and 3.2 at week 192, 2.8 and 3.2 at week 240, and 2.9 and 3.2 at week $288 .{ }^{34}$ Overall, patients on natalizumab generally experienced stable EDSS scores and a low annualized relapse rate over time. Patients initially randomized to 2 years of treatment with natalizumab in the Phase III clinical trials retained their lower EDSS scores compared with those initially randomized to placebo. This suggests important advantages of early treatment with natalizumab.

TOP is a 10-year prospective, multinational, openlabel, post-marketing, observational study of the long-term clinical safety and efficacy of natalizumab in the European, Australian, and Canadian settings. Patients must have active RRMS and be natalizumab-naïve ( $\leq 3$ doses prior to enrollment), but may have received other diseasemodifying therapies prior to natalizumab. A preliminary report on the TOP study was presented in June 2011. At that time, 3,484 patients from 15 countries were enrolled. 
Overall, the mean EDSS score was 3.5 at baseline and 3.4 after 3 years. The overall annualized relapse rate was significantly decreased from baseline (1.98) to post-baseline $(0.28, P<0.0001)$. Annualized relapse rates at baseline were similar (1.91-2.03) regardless of the patient's previous therapy, but after 3 years of treatment with natalizumab, the annualized relapse rates differed significantly according to pre-enrollment therapy $(P<0.0001)$, ie, therapy-naïve $(0.16)$, prior IFN (0.20), prior glatiramer acetate $(0.23)$, prior IFN/ glatiramer acetate or glatiramer acetate/IFN $(0.25)$, and prior immunosuppression (0.34). ${ }^{35}$

After this general update, two subsequent updates have been presented. One update reported TOP results obtained in the UK until June 2012. ${ }^{36}$ At that time, 117 patients were enrolled in the UK and received a median of 15 (range 1-27) natalizumab infusions. The median number of relapses in the year prior to treatment with natalizumab was $2.0,24.8 \%$ of the patients had one relapse, and $75.2 \%$ had more than one relapse. The overall annualized relapse rate decreased from 2.26 at baseline to 0.38 on treatment $(P<0.0001)$. The annualized relapse rate decreased significantly from baseline regardless of baseline treatment history and relapse history. In treatment-naïve patients, the relapse rate was 2.54 at baseline versus 0.48 on treatment $(P<0.0001)$. In patients previously treated with one disease-modifying therapy, the relapse rate was 2.14 at baseline versus 0.36 on treatment $(P<0.0001)$. In patients with more than one prior disease-modifying treatment, the relapse rate was 2.00 at baseline versus 0.26 on treatment $(P=0.0003)$. Regarding history of relapse, in patients with one relapse in the prior year, the relapse rate was 1.00 at baseline versus 0.27 on treatment $(P<0.001)$, and in patients with more than one relapse in the prior year, the relapse rate was 2.67 at baseline versus 0.43 on treatment $(P<0.0001)$. EDSS scores were stable, with a mean of 4.2 at baseline, 4.0 at month $6,4.4$ at year 1 , and 4.3 at year 2. This interim analysis of TOP results in the UK indicated that treatment with natalizumab improves the annualized relapse rate, regardless of baseline treatment or relapse history, and stabilizes EDSS scores. ${ }^{36}$

A second observational study reported TOP results obtained in Germany until February 2012. ${ }^{37}$ In this study, the annualized relapse rate in the year prior to treatment with natalizumab was 2.2, the EDSS was 3.5, and the Demtect cognitive function score at baseline was 14.9. After treatment with natalizumab, the relapse rate decreased to 0.14 , the EDSS stabilized at 3.5, and the Demtect score increased to
16.0. This interim study confirms the sustained efficacy of natalizumab in reducing clinical disease activity.

\section{Safety of natalizumab and impact on quality of life Progressive multifocal leukoencephalopathy}

PML is a demyelinating disorder of the CNS caused by John Cunningham virus (JCV) infection. ${ }^{38,39} \mathrm{JCV}$ is a ubiquitous virus, which infects $60 \%-80 \%$ of the population worldwide without clinical consequences, but can cause PML under circumstances of immunocompromise and especially impaired CD4+ T cell function, such as in late-stage human immunodeficiency virus infection, hematological malignancies, and organ transplantation, and also in clinically inconspicuous idiopathic CD4+ lymphopenia. ${ }^{38,40,41}$ PML has recently emerged as a serious adverse event during monoclonal antibody treatment of autoimmune diseases, especially in MS patients treated with natalizumab. The first two cases of PML in natalizumab-treated patients developed during premarketing studies, with one case occurring in the SENTINEL trial after 28 doses of natalizumab and the other in the open-label extension of SENTINEL after 37 doses of natalizumab. ${ }^{11,12}$ One patient died from PML and the other patient with PML progressed rapidly. These cases were followed by a case of PML after eight infusions of natalizumab in a patient with Crohn's disease. ${ }^{13}$

As mentioned above, after these PML cases, the manufacturer voluntarily suspended natalizumab in 2005 pending a safety review. In March 2006, an extensive safety study of 3,116 patients with MS, Crohn's disease, or rheumatoid arthritis who received treatment with natalizumab were assessed for PML. ${ }^{42}$ Of these, 44 were referred to the expert panel because of clinical findings of possible PML, abnormalities on MRI, or a high plasma load of JCV. No patient had detectable JCV DNA in cerebrospinal fluid. PML was ruled out in 43 of the 44 patients, but could not be ruled out in one patient because cerebrospinal fluid and follow-up MRI were not available. ${ }^{42}$ No new PML cases were identified in this study, suggesting a risk of PML of roughly one in 1,000 patients treated with natalizumab for a mean of 17.9 months.

Based on this study, it was considered that the estimated risk of PML was acceptable given the demonstrably outstanding therapeutic benefits of natalizumab, and the drug was reintroduced in the market in June 2006 and approved by the FDA and European Medicines Agency 
for highly active RRMS. Since then, the number of cases of PML has continued to increase. As of February 2012, 212 confirmed PML cases among 99,571 patients treated with natalizumab were reported, giving an incidence of 2.1 cases per 1,000 patients. ${ }^{43}$ Twenty-two percent of these PML patients died and $40 \%$ of the evaluable survivors had severe disability. As of March 2013, the number of patients with confirmed PML was 343 among more than 112,000 treated patients, giving a risk of PML associated with natalizumab of 2.96 cases per 1,000 patients. ${ }^{44}$ The mean duration of treatment in these patients was 39 months. The most recent media release, in December $2013,{ }^{45}$ indicates an overall incidence of PML in natalizumab-treated patients of 3.41 cases per 1,000 patients.

In general, the outcome of natalizumab-associated PML is better than in PML associated with human immunodeficiency virus. Two case series studies demonstrated that around $70 \%$ of natalizumab-associated PML cases survived and that survival is correlated with younger age, lower EDSS prior to diagnosis, lower JCV load at diagnosis, and more localized brain involvement on MRI at the time of diagnosis. ${ }^{46,47}$ The most recent media release from December 2013 indicates that $77 \%$ of the PML patients are alive, with varying levels of disability. However, despite this better outcome of PML in MS patients, cessation of natalizumab therapy in these patients could have serious negative consequences. Unlike general immunosuppression, natalizumab therapy selectively compromises immune surveillance only in the CNS and gut, and only during treatment. Cessation of natalizumab therapy in MS patients who develop PML re-establishes immune surveillance in the CNS and leads to an inflammatory response known as PML immune reconstitution inflammatory syndrome, which allows efficient destruction of JCV-infected cells and eradication of the virus, ${ }^{48,49}$ but can also lead to rapid deterioration of the patient's clinical state and death in about $30 \%-50 \%$ of cases. ${ }^{49}$ The cellular and molecular pathogenesis of PML immune reconstitution inflammatory syndrome is not completely understood, but histological analysis of biopsy samples demonstrated that both $\mathrm{CD} 8^{50}$ and $\mathrm{CD} 4^{51}$ inflammation dominated the $\mathrm{T}$ cell infiltrate.

During 8 years of use of natalizumab as a treatment for MS, considerable progress has been made in identification of risk factors for PML and approaches to risk minimization. Positive status with respect to anti-JCV antibodies, prior use of immunosuppressants, and increased duration of treatment with natalizumab (more than 2 years) are the main PML risk factors identified. ${ }^{43}$ The estimated incidence of PML in patients with all three risk factors was 11.1 cases per 1,000 patients, compared with an estimated incidence of 0.09 cases per 1,000 in the group of patients negative for JCV antibodies. ${ }^{43}$ Based on this risk stratification, treatment recommendations have been proposed ${ }^{52}$ that include testing for JCV antibodies prior to starting treatment with natalizumab and every 6 months thereafter. As of December 2013, results of the anti-JCV antibody assay have been reliable in stratifying PML risk; 99\% of PML patients with available pre-PML samples tested positive for anti-JCV antibodies.

The incidence of PML in natalizumab-treated patients is higher in Europe than in the USA, and the treatment duration beyond which the risk for PML increases is also longer in the USA. Although the reason for this difference is unknown, it has been proposed that it might be related to body mass index. It has been hypothesized that a low body mass might translate into higher concentrations of natalizumab in plasma, higher or more complete VLA-4 saturation rates in immune cells, and a consequently decreased immunosurveillance of the CNS and a higher incidence of PML. ${ }^{53}$ Reducing the natalizumab dose or increasing the interval between infusions may reduce this risk.

Regarding biomarkers for risk of PML, it was recently reported that the percentage of L-selectin-expressing CD4+ $\mathrm{T}$ cells was significantly lower in patients on long-term treatment with natalizumab (40.2\%) when compared with patients not receiving natalizumab $(47.2 \%, P=0.016)$ and healthy controls $(61.0 \%, P<0.0001) .{ }^{54}$ This unusually low percentage correlated with the risk of developing PML in the patient group with available pre-PML samples when compared with natalizumab-treated patients without PML $(P \leq 0.0001)$. These results suggest that a low percentage of L-selectin-expressing CD4+ T cells might be useful as a biomarker for individual PML risk.

It has also been suggested that natalizumab might reduce $\mathrm{T}$ cell responses against JCV in peripheral blood, facilitating reactivation of JCV. It has been reported that subclinical reactivation of JCV occurs frequently in natalizumab-treated patients and that viral shedding is associated with a transient drop in JCV-specific cellular immune responses, ${ }^{55}$ suggesting that monitoring $\mathrm{JCV}$-specific $\mathrm{T}$ cell responses might be an interesting biomarker for risk of PML. However, neither the reduced $\mathrm{T}$ cell response nor viral reactivation in peripheral blood during treatment with natalizumab has been reproduced in other studies. ${ }^{56,57}$

Treatment with natalizumab not only compromises immune surveillance of the CNS, but also mobilizes 
lymphoid hematopoietic precursor cells from the bone marrow $^{58-61}$ and induces significant sustained phenotypic changes in the immune cell composition of peripheral blood, such as an increase in $\mathrm{T}$ cells, natural killer cells, and especially $\mathrm{B}$ cells, and a decrease in monocytes, ${ }^{61-64}$ suggesting that there is no desensitization effect after prolonged exposure to natalizumab. ${ }^{65}$ Mobilization of lymphoid precursors and B cells might contribute to development of PML, given that this might result in a significant increase in cells that are in principle able to produce and spread progeny virus. Monitoring circulating JCV-infected hematopoietic cells and B cells might be an interesting biomarker for risk of PML and deserves further investigation.

\section{Other issues with natalizumab} Short-term side effects

Natalizumab is generally well tolerated, and few short-term side effects were reported in the Phase III AFFIRM and SENTINEL clinical trials..$^{9,10}$ The more common reported side effects were nonserious, and included fatigue, anxiety, pharyngitis, sinus congestion, peripheral edema, and allergic reactions. Allergic reactions are often associated with the presence of antibodies against natalizumab. Data from the Phase III clinical trials indicated a higher percentage of allergic reactions in treated individuals than in those on placebo, and around $10 \%$ of treated patients developed anti-natalizumab antibodies. ${ }^{9} 10$ Persistently high anti-natalizumab antibody titers are associated with a lack of drug efficacy, a reduction in the monoclonal antibody concentration in serum, and infusion-related hypersensitivity reactions. ${ }^{66,67}$ The short-term side effects of natalizumab in these clinical trials have been previously reviewed in detail. $^{15,16}$

Natalizumab, like other $\mathrm{T}$ cell immunomodulatory treatments, has been associated with liver injury. Although this is not a common side effect, some cases have been reported of MS patients who developed serious liver injury after their first natalizumab infusion. ${ }^{68,69}$ Patients developed increased serum aminotransferases and hyperbilirubinemia and sometimes signs of autoimmune hepatitis, such as autoantibodies and liver inflammation. These adverse events normally appeared after the first natalizumab infusion and remitted after discontinuation of treatment. Although the mechanism by which natalizumab might induce liver damage is unknown, it is recommended to monitor for signs of autoimmune hepatitis or atypical viral infections before and during treatment with natalizumab.

\section{Long-term side effects}

Long-term impaired immunosurveillance in MS patients treated with natalizumab has been associated with several opportunistic infections other than JCV, although a higher risk has not been proven. Human herpesvirus-6 (HHV-6) is a pleiotropic $\beta$-herpesvirus that infects cells in the CNS. HHV-6 is commonly reactivated in situations of immunosuppression and has been associated with MS. ${ }^{70}$ Several lines of evidence, including an increase in the level of HHV-6-specific antibodies in serum and an increase in HHV-6 DNA in the cerebrospinal fluid of natalizumabtreated MS patients, suggest that HHV-6 might reactivate on treatment with natalizumab. ${ }^{71,72}$ Herpes simplex and varicella zoster CNS infections have recently been reported in 20 natalizumab-treated MS patients. ${ }^{73,74}$ Finally, a single case of ocular toxoplasmosis has been reported after 11 months of treatment with natalizumab. ${ }^{75}$ Toxoplasma gondii infects $30 \%$ of the population without causing symptoms, but in immunocompromised individuals can reactivate and lead to organ damage. ${ }^{76}$

The relationship between long-term treatment with natalizumab and a higher susceptibility to developing malignancy is still under debate. Several cases of malignant melanoma while on treatment with natalizumab have been reported..$^{77-80}$ However, the prevalence of melanoma was not different when comparing natalizumab-treated and untreated MS patients. ${ }^{78}$ Single cases of primary CNS lymphoma and peripheral $\mathrm{T}$ cell lymphoma have been reported in natalizumab-treated MS patients, ${ }^{81,82}$ although a direct cause-effect relationship has not been demonstrated. Other hematologic changes, such as hypereosinophilia, immune-mediated acute hemolytic anemia, and immune thrombocytopenic purpura, have occasionally been reported in natalizumab-treated MS patients. ${ }^{16}$

\section{Impact on quality of life}

Not only the risk of PML, but also other adverse events, such as hypersensitivity reactions, recurrent infections, or malignancies, or other conditions, such as pregnancy, might render it advisable to discontinue natalizumab. ${ }^{83}$ Given that natalizumab is a treatment with high benefits along with very severe risks, experts have advocated an informed reconsent for patients after 2 years of treatment with natalizumab. Although a good understanding of the benefits and risks is important regarding the decision whether to continue or stop treatment, the perception of risk differs between patients and neurologists. In a study published in 2010, 
when the estimated risk for natalizumab-induced PML in MS patients treated for more than 2 years was about one in 1,000, patients perceived MS as a malignant disease, so were willing to accept a considerably higher PML risk than neurologists. ${ }^{84}$ Identification in recent years of JCV seropositivity, duration of treatment with natalizumab, and prior immunosuppression as risk factors, has modified this acceptance of risk. Although the large majority of JCV-seropositive patients are still willing to continue treatment, seropositive patients have elevated anxiety levels, are less secure about their decision to continue treatment, feel less safe, and are more afraid of PML. ${ }^{85}$

One important complication of cessation of natalizumab with crucial consequences for patients is that it is presently not known which treatment strategy is the more appropriate to follow after stopping treatment with natalizumab. ${ }^{83}$ It is known that disease activity returns to pretreatment levels or even above within 4-7 months from the last natalizumab infusion, so patients stopping natalizumab are at considerable risk of rebound relapse/inflammatory activity and worsening MS-related disability. ${ }^{86}$ Several strategies have been used to avoid disease activity after discontinuation of natalizumab. One of these strategies, which unfortunately has not been very effective, was use of methylprednisolone as a bridge before switching to glatiramer acetate or IFN- $\beta$. Better results have been obtained in some case series using fingolimod as subsequent therapy, although long-term data on the efficacy and safety of fingolimod after cessation of natalizumab are still missing. Other therapies available, such as fumarate, might represent a good alternative to optimize escalation treatment for patients who stop natalizumab, but further long-term studies are needed.

The clinical experience with natalizumab has provided important lessons. While the drug continues to be perceived as highly effective and well tolerated overall, the risk of PML remains an important safety concern, that is not solved at present despite risk stratification algorithms. Accordingly, last December, the FDA approved a label update, announcing that natalizumab is no longer generally recommended for those who have responded inadequately to or are unable to tolerate alternative MS therapy. ${ }^{87}$ Further important questions that merit more detailed investigation are whether certain markers can allow us to identify patients who will show severe rebound disease activity after cessation of natalizumab, how to switch over from natalizumab to other drugs, and over what periods of time.

\section{Disclosure}

RM has previously received an unrestricted grant by Biogen Idec as well as compensation for presentations and advisory function by Biogen Idec, Merck \& Serono, Novartis, and Teva. The authors report no other conflicts of interest in this work.

\section{References}

1. Sospedra M, Martin R. Immunology of multiple sclerosis. Annu Rev Immunol. 2005;23:683-747.

2. Lublin FD, Reingold SC. Defining the clinical course of multiple sclerosis: results of an international survey. National Multiple Sclerosis Society (USA) Advisory Committee on Clinical Trials of New Agents in Multiple Sclerosis. Neurology. 1996;46(4):907-911.

3. Frischer JM, Bramow S, Dal-Bianco A, et al. The relation between inflammation and neurodegeneration in multiple sclerosis brains. Brain. 2009;132 Pt 5:1175-1189.

4. del Pilar Martin M, Cravens PD, Winger R, et al. Decrease in the numbers of dendritic cells and CD4+ T cells in cerebral perivascular spaces due to natalizumab. Arch Neurol. 2008;65(12):1596-1603.

5. Stuve O, Marra CM, Jerome KR, et al. Immune surveillance in multiple sclerosis patients treated with natalizumab. Ann Neurol. 2006;59(5): 743-747.

6. Yednock TA, Cannon C, Fritz LC, Sanchez-Madrid F, Steinman L, Karin N. Prevention of experimental autoimmune encephalomyelitis by antibodies against alpha 4 beta 1 integrin. Nature. 1992;356(6364):63-66.

7. Bauer M, Brakebusch C, Coisne C, et al. Beta1 integrins differentially control extravasation of inflammatory cell subsets into the CNS during autoimmunity. Proc Natl Acad Sci U S A. 2009;106(6):1920-1925.

8. Niino M, Bodner C, Simard ML, et al. Natalizumab effects on immune cell responses in multiple sclerosis. Ann Neurol. 2006;59(5):748-754

9. Polman CH, O'Connor PW, Havrdova E, et al. A randomized, placebocontrolled trial of natalizumab for relapsing multiple sclerosis. $N$ Engl J Med. 2006;354(9):899-910.

10. Rudick RA, Stuart WH, Calabresi PA, et al. Natalizumab plus interferon beta-1a for relapsing multiple sclerosis. $N$ Engl $J$ Med. 2006;354(9):911-923.

11. Langer-Gould A, Atlas SW, Green AJ, Bollen AW, Pelletier D. Progressive multifocal leukoencephalopathy in a patient treated with natalizumab. $N$ Engl J Med. 2005;353(4):375-381.

12. Kleinschmidt-DeMasters BK, Tyler KL. Progressive multifocal leukoencephalopathy complicating treatment with natalizumab and interferon beta-1a for multiple sclerosis. $N$ Engl J Med. 2005;353(4): 369-374.

13. Van Assche G, Van Ranst M, Sciot R, et al. Progressive multifocal leukoencephalopathy after natalizumab therapy for Crohn's disease. N Engl J Med. 2005;353(4):362-368.

14. Goodman AD, Rossman H, Bar-Or A, et al. GLANCE: results of a phase 2, randomized, double-blind, placebo-controlled study. Neurology. 2009;72(9):806-812.

15. McCormack PL. Natalizumab: a review of its use in the management of relapsing-remitting multiple sclerosis. Drugs. 2013;73(13): $1463-1481$.

16. Derfuss T, Kuhle J, Lindberg R, Kappos L. Natalizumab therapy for multiple sclerosis. Semin Neurol. 2013;33(1):26-36.

17. Lanzillo R, Bonavita S, Quarantelli M, et al. Natalizumab is effective in multiple sclerosis patients switching from other disease modifying therapies in clinical practice. Neurol Sci. 2013;34(4):521-528.

18. Prosperini L, Gianni C, Leonardi L, et al. Escalation to natalizumab or switching among immunomodulators in relapsing multiple sclerosis. Mult Scler. 2012;18(1):64-71. 
19. Putzki N, Yaldizli O, Buhler R, Schwegler G, Curtius D, Tettenborn B. Natalizumab reduces clinical and MRI activity in multiple sclerosis patients with high disease activity: results from a multicenter study in Switzerland. Eur Neurol. 2010;63(2):101-106.

20. Oturai AB, Koch-Henriksen N, Petersen T, Jensen PE, Sellebjerg F, Sorensen PS. Efficacy of natalizumab in multiple sclerosis patients with high disease activity: a Danish nationwide study. Eur J Neurol. 2009;16(3):420-423.

21. Holmen C, Piehl F, Hillert J, et al. A Swedish national post-marketing surveillance study of treatment with natalizumab in multiple sclerosis. Mult Scler. 2011;17(6):708-719.

22. Belachew S, Phan-Ba R, Bartholome E, et al. Natalizumab induces a rapid improvement of disability status and ambulation after failure of previous therapy in relapsing-remitting multiple sclerosis. Eur J Neurol. 2011;18(2):240-245.

23. Balcer LJ, Galetta SL, Calabresi PA, et al. Natalizumab reduces visual loss in patients with relapsing multiple sclerosis. Neurology. 2007;68(16):1299-1304.

24. Meuth SG, Bittner S, Seiler C, Gobel K, Wiendl H. Natalizumab restores evoked potential abnormalities in patients with relapsing-remitting multiple sclerosis. Mult Scler. 2011;17(2):198-203.

25. Lang C, Reiss C, Maurer M. Natalizumab may improve cognition and mood in multiple sclerosis. Eur Neurol. 2012;67(3):162-166.

26. Iaffaldano P, Viterbo RG, Paolicelli D, et al. Impact of natalizumab on cognitive performances and fatigue in relapsing multiple sclerosis: a prospective, open-label, two years observational study. PLoS One. 2012;7(4):e35843.

27. Mattioli F, Stampatori C, Capra R. The effect of natalizumab on cognitive function in patients with relapsing-remitting multiple sclerosis: preliminary results of a 1-year follow-up study. Neurol Sci. 2011;32(1): 83-88.

28. Rinaldi F, Calabrese M, Seppi D, Puthenparampil M, Perini P, Gallo P. Natalizumab strongly suppresses cortical pathology in relapsingremitting multiple sclerosis. Mult Scler. 2012;18(12):1760-1767.

29. Gunnarsson M, Malmestrom C, Axelsson M, et al. Axonal damage in relapsing multiple sclerosis is markedly reduced by natalizumab. Ann Neurol. 2011;69(1):83-89.

30. Kamat SA, Rajagopalan K, Stephenson JJ, Agarwal S. Impact of natalizumab on patient-reported outcomes in a clinical practice setting: a cross-sectional survey. Patient. 2009;2(2):105-112.

31. Stephenson JJ, Kern DM, Agarwal SS, et al. Impact of natalizumab on patient-reported outcomes in multiple sclerosis: a longitudinal study. Health Qual Life Outcomes. 2012;10:155.

32. Olofsson S, Wickstrom A, Hager GlenngardA, Persson U, SvenningssonA. Effect of treatment with natalizumab on ability to work in people with multiple sclerosis: productivity gain based on direct measurement of work capacity before and after 1 year of treatment. BioDrugs. 2011;25(5):299-306.

33. Svenningsson A, Falk E, Celius EG, et al. Natalizumab treatment reduces fatigue in multiple sclerosis. Results from the TYNERGY trial; a study in the real life setting. PLoS One. 2013;8(3):e58643.

34. Rudick R, Goodman A, Kappos L, et al. Six-year natalizumab safety and efficacy data from STRATA study. Abstract presented at the 29th Congress of the European Commitee for Treatment and Research in Multiple Sclerosis, Copenhagen, Denmark, October 2-5, 2013.

35. Kappos L, Belachew S, Butzkueven H, et al. Long-term safety and efficacy and association between baseline treatment history and postbaseline relapses in multiple sclerosis patients treated with natalizumab in the TYSABRI Observational Program (TOP). Neurology. 2012;78 Suppl:1. Available from: http://www.neurology.org/cgi/content/meeting_abstract/78/1_MeetingAbstracts/P04.134. Accessed March 3, 2014.

36. Hanna J, Rosen JP, Smethurst C. Efficacy and safety of treatment with natalizumab for relapsing-remitting multiple sclerosis: interim resutls of the Tysabri Observational Programme in the UK. J Neurol Neurosurg Psychiatry. 2013;84:e2.
37. Maurer M, Wiendl H, Heesen C, et al. Observational Program Tysabri 24 plus: evaluating efficacy and safety of natalizumab therapy beyond two years. Neurology. 2012;78 Suppl:1. Available from: http://www. neurology.org/cgi/content/meeting_abstract/80/1_MeetingAbstracts/ P01.161?sid=6f1a22db-3684-4c80-90dd-e8e56a2321b3. Accessed March 3, 2014.

38. Major EO. Progressive multifocal leukoencephalopathy in patients on immunomodulatory therapies. Ann Rev Med. 2010;61:35-47.

39. Tan CS, Koralnik IJ. Progressive multifocal leukoencephalopathy and other disorders caused by JC virus: clinical features and pathogenesis. Lancet Neurol. 2010;9(4):425-437.

40. Gheuens S, Pierone G, Peeters P, Koralnik IJ. Progressive multifocal leukoencephalopathy in individuals with minimal or occult immunosuppression. J Neurol Neurosurg Psychiatry. 2010;81(3):247-254.

41. Puri V, Chaudhry N, Gulati P, Patel N, Tatke M, Sinha S. Progressive multifocal leukoencephalopathy in a patient with idiopathic CD4+T lymphocytopenia. Neurol India. 2010;58(1):118-121.

42. Yousry TA, Major EO, Ryschkewitsch C, et al. Evaluation of patients treated with natalizumab for progressive multifocal leukoencephalopathy. N Engl J Med. 2006;354(9):924-933.

43. Bloomgren G, Richman S, Hotermans C, et al. Risk of natalizumabassociated progressive multifocal leukoencephalopathy. $N$ Engl J Med. 2012;366(20):1870-1880

44. Barts and the London School of Medicine and Dentistry. Multiple Sclerosis Research: natalizumab-associated PML update: Mar 2013. Available from: http://multiple-sclerosis-research.blogspot. co.nz/2013/04/natalizumab-associated-pml-update-march.html. Accessed February 27, 2014

45. Biogen idec. TYSABRI (natalizumab) Benefit/Risk Update \& PML Risk Stratification FOR HEALTHCARE PROFESSIONALS ONLY TY-PAN-0597(7) [press release]; 2013 [December]. Available from: http://de.slideshare.net/gavingiovannoni/tysabri-benefit-risk-updatedecember-2013. Accessed March 24, 2014.

46. Vermersch P, Kappos L, Gold R, et al. Clinical outcomes of natalizumabassociated progressive multifocal leukoencephalopathy. Neurology. 2011;76(20):1697-1704.

47. Clifford DB, De Luca A, Simpsom DM, Arendt G, Giovannoni G, Nath A. Natalizumab-associated progressive multifocal leukoencephalopathy in pateints with multiple sclerosis: lessons from 28 cases. Lancet Neurol. 2010;9(4):438-446.

48. Koralnik IJ. Progressive multifocal leukoencephalopathy revisited: has the disease outgrown its name? Ann Neurol. 2006;60(2):162-173.

49. Tan K, Roda R, Ostrow L, McArthur J, Nath A. PML-IRIS in patients with HIV infection: clinical manifestations and treatment with steroids. Neurology. 2009;72(17):1458-1464.

50. Metz I, Radue EW, Oterino A, et al. Pathology of immune reconstitution inflammatory syndrome in multiple sclerosis with natalizumab-associated progressive multifocal leukoencephalopathy. Acta Neuropathol. 2012;123(2):235-245.

51. Aly L, Yousef S, Schippling S, et al. Central role of JC virus-specific CD4+ lymphocytes in progressive multi-focal leucoencephalopathyimmune reconstitution inflammatory syndrome. Brain. 2011;134 Pt 9: 2687-2702.

52. Sorensen PS, Bertolotto A, Edan G, et al. Risk stratification for progressive multifocal leukoencephalopathy in patients treated with natalizumab. Mult Scler. 2012;18(2):143-152.

53. Foley J. Natalizumab related PML: an evolving risk stratification paradigm. Abstract presented at the 65th Annual Meeting of the American Academy of Neurology, San Diego, CA, USA, March 16-23, 2013.

54. Schwab N, Schneider-Hohendorf T, Posevitz V, et al. L-selectin is a possible biomarker for individual PML risk in natalizumab-treated MS patients. Neurology. 2013;81(10):865-871.

55. Chen Y, Bord E, Tompkins T, et al. Asymptomatic reactivation of JC virus in patients treated with natalizumab. NEngl J Med. 2009;361(11): 1067-1074. 
56. Jilek S, Jaquiery E, Hirsch HH, et al. Immune responses to JC virus in patients with multiple sclerosis treated with natalizumab: a crosssectional and longitudinal study. Lancet Neurol. 2010;9(3):264-272.

57. Rudick RA, O'Connor PW, Polman CH, et al. Assessment of JC virus DNA in blood and urine from natalizumab-treated patients. Ann Neurol. 2010;68(3):304-310.

58. Bonig H, Wundes A, Chang KH, Lucas S, Papayannopoulou T. Increased numbers of circulating hematopoietic stem/progenitor cells are chronically maintained in patients treated with the CD49d blocking antibody natalizumab. Blood. 2008;111(7):3439-3441.

59. Zohren F, Toutzaris D, Klarner V, Hartung HP, Kieseier B, Haas R. The monoclonal anti-VLA-4 antibody natalizumab mobilizes CD34+ hematopoietic progenitor cells in humans. Blood. 2008;111(7): 3893-3895.

60. Jing D, Oelschlaegel U, Ordemann R, et al. CD49d blockade by natalizumab in patients with multiple sclerosis affects steady-state hematopoiesis and mobilizes progenitors with a distinct phenotype and function. Bone Marrow Transplant. 2010;45(10):1489-1496.

61. Planas R, Jelčić I, Schippling S, Martin R, Sospedra M. Natalizumab treatment perturbs memory- and marginal zone-like $\mathrm{b}$ cell homing in secondary lymphoid organs in multiple sclerosis. Eur J Immunol. 2012;42(3):790-798

62. Krumbholz M, Meinl I, Kumpfel T, Hohlfeld R, Meinl E. Natalizumab disproportionately increases circulating pre-B and B cells in multiple sclerosis. Neurology. 2008;71(17):1350-1354.

63. Putzki N, Baranwal MK, Tettenborn B, Limmroth V, Kreuzfelder E. Effects of natalizumab on circulating B cells, T regulatory cells and natural killer cells. Eur Neurol. 2010;63(5):311-317.

64. Skarica M, Eckstein C, Whartenby KA, Calabresi PA. Novel mechanisms of immune modulation of natalizumab in multiple sclerosis patients. $J$ Neuroimmunol. 2011;235(1-2):70-76.

65. Marousi S, Karkanis I, Kalamatas T, Travasarou M, Paterakis G, Karageorgiou CE. Immune cells after prolonged natalizumab therapy: implications for effectiveness and safety. Acta Neurol Scand. 2013;128(1):e1-e5.

66. Stuve O, Bennett JL. Pharmacological properties, toxicology and scientific rationale for the use of natalizumab (Tysabri) in inflammatory diseases. CNS Drug Rev. 2007;13(1):79-95.

67. Vennegoor A, Rispens T, Strijbis EM, et al. Clinical relevance of serum natalizumab concentration and anti-natalizumab antibodies in multiple sclerosis. Mult Scler. 2013;19(5):593-600.

68. Lisotti A, Azzaroli F, Brillanti S, Mazzella G. Severe acute autoimmune hepatitis after treatment with natalizumab. Dig Liver Dis. 2012;44(4):356-357.

69. Bezabeh S, Flowers CM, Kortepeter C, Avigan M. Clinically significant liver injury in patients treated with natalizumab. Aliment Pharmacol Ther. 2010;31(9):1028-1035.

70. Alvarez-Lafuente R, De las Heras V, Bartolome M, Picazo JJ, Arroyo R. Relapsing-remitting multiple sclerosis and human herpesvirus 6 active infection. Arch Neurol. 2004;61(10):1523-1527.
71. Stuve O. The effects of natalizumab on the innate and adaptive immune system in the central nervous system. J Neurol Sci. 2008;274(1-2): 39-41.

72. Yao K, Gagnon S, Akhyani N, et al. Reactivation of human herpesvirus-6 in natalizumab treated multiple sclerosis patients. PLoS One. 2008;3(4):e2028.

73. Fine AJ, Sorbello A, Kortepeter C, Scarazzini L. Central nervous system herpes simplex and varicella zoster virus infections in natalizumabtreated patients. Clin Infect Dis. 2013;57(6):849-852.

74. Kwiatkowski A, Gallois J, Bilbault N, Calais G, Mackowiak A, Hautecoeur P. Herpes encephalitis during treatment with natalizumab in multiple sclerosis. Mult Scler. 2012;18(6):909-911.

75. Zecca C, Nessi F, Bernasconi E, Gobbi C. Ocular toxoplasmosis during treatment with natalizumab. Neurology. 2009;73(17):1418-1419.

76. Stuve O, Wiendl H. Iatrogenic immunosuppression with biologics in MS: expecting the unexpected? Neurology. 2009;73(17):1346-1347.

77. Mullen JT, Vartanian TK, Atkins MB. Melanoma complicating treatment with natalizumab for multiple sclerosis. $N$ Engl J Med. 2008;358(6):647-648

78. Bergamaschi R, Montomoli C. Melanoma in multiple sclerosis treated with natalizumab: causal association or coincidence? Mult Scler. 2009;15(12):1532-1533.

79. Ismail A, Kemp J, Sharrack B. Melanoma complicating treatment with natalizumab (tysabri) for multiple sclerosis. $J$ Neurol. 2009;256(10):1771-1772.

80. Laroni A, Bedognetti M, Uccelli A, Capello E, Mancardi GL. Association of melanoma and natalizumab therapy in the Italian MS population: a second case report. Neurol Sci. 2011;32(1):181-182.

81. Schweikert A, Kremer M, Ringel F, et al. Primary central nervous system lymphoma in a patient treated with natalizumab. Ann Neurol. 2009;66(3):403-406.

82. Schowinsky J, Corboy J, Vollmer T, Kleinschmidt-DeMasters BK. Natalizumab-associated complication? First case of peripheral T cell lymphoma. Acta Neuropathol. 2012;123(5):751-752.

83. Havla J, Kleiter I, Kumpfel T. Bridging, switching or drug holidays how to treat a patient who stops natalizumab? Ther Clin Risk Manag. 2013;9:361-369.

84. Heesen C, Kleiter I, Nguyen F, et al. Risk perception in natalizumabtreated multiple sclerosis pateints and their neurologists. Mult Scler. 2010;16:1507-1512.

85. van Rossum JA, Vennegoor A, Balk L, Uitdehaag BM, Polman $\mathrm{CH}$, Killestein J. Safety, anxiety and natalizumab continuation in JC virus-seropositive MS patients. Mult Scler. 2013;20(1):108-111.

86. O’Connor PW, Goodman A, Kappos L, et al. Disease activity return during treatment with natalizumab interruption in patients with multiple sclerosis. Neurology. 2011;76(22):1858-1865.

87. Drug and Device Safety. Available from: http://www.aan.com/practice/ patient-safety/drug-and-device-safety/. Accessed March 2, 2014.
Patient Related Outcome Measures

\section{Publish your work in this journal}

Patient Related Outcome Measures is an international, peer-reviewed, open access journal focusing on treatment outcomes specifically relevant to patients. All aspects of patient care are addressed within the journal and practitioners from all disciplines are invited to submit their work as well as healthcare researchers and patient support groups.

\section{Dovepress}

The manuscript management system is completely online and includes a very quick and fair peer-review system. Visit http://www.dovepress. com/testimonials.php to read real quotes from published authors. 